\begin{tabular}{|c|c|}
\hline & $\begin{array}{l}\text { International Journal of Trend in Scientific } \\
\text { Research and Development (IJTSRD) }\end{array}$ \\
\hline 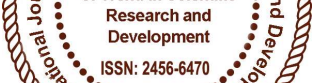 & International Open Access Journal \\
\hline 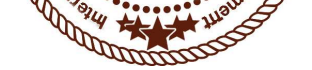 & ISSN No: 2456 - 6470 | www.ijtsrd.com | Volume - 2 | Issue - 2 \\
\hline
\end{tabular}

\title{
The coating on Al6061 Aluminium alloy surface with WC/Ni powder compact electrode using electrical discharge machining
}

\author{
U Elaiyarasan \\ Department of Manufacturing Engineering, \\ Annamalai University, Chidambaram, India
}

\begin{abstract}
S Karthi
Department of Mechanical Engineering, Periyar

Maniammai Institute of Science \& Technology

(PMIST), Thanjavur, Tamil Nadu, India
\end{abstract}

\begin{abstract}
N Sivaharinathan
Department of Mechanical Engineering, Periyar

Maniammai Institute of Science \& Technology

(PMIST), Thanjavur, Tamil Nadu, India

\section{A Mohamed Ismail}

Department of Mechanical Engineering, Periyar

Maniammai Institute of Science \& Technology

(PMIST), Thanjavur, Tamil Nadu, India
\end{abstract}

\section{ABSTRACT}

EDM is an unconventional machining process widely used for machining tough material. A special aspect of EDM is surface modification by transferring the tool electrode material to workpiece surface. In the present work, electrode prepared with tungsten carbide (WC) and nickel (Ni) by powder metallurgy route as tool and Al6061 as workpiece substrate. By changing the polarity of EDM (workpiece as cathode and tool as anode), the hard carbide layer of $\mathrm{WC} / \mathrm{Ni}$ tool has been deposited on the workpiece. The influence of compaction load through $\mathrm{P} / \mathrm{M}$ method, discharge current and pulse on time during electrical discharge coating (EDC) on metal transfer rate (MTR) and tool wear rate (TWR) have been studied. As design of experiment, face centered central composite of response surface methodology (RSM) has been adopted to study the influence of various parameter on EDC.

Keywords: EDM, Surface modification, powder metallurgy, EDC, RSM, MTR, TWR.

\section{Introduction}

EDM (Electrical discharge machining) is an electro thermal process widely used for machining the highly hardened material by supplying series of electric spark on the workpiece. EDM can be used to perform in precision operation in various fields of industries like die and mould making industries, field of automotive and aircraft, making surgical components industries $[1,2]$. Nowadays application of EDM has extended to surface modification for making protective layer on the workpiece surface fixing worn region. This protective layer making process involved by EDM is called EDC (Electrical Discharge Coating) [3-5]. The hard carbide layer can be created on the workpiece through chemical reaction between tool electrode and decomposed carbon particles from dielectric under high temperature. Generally tool electrode has been prepared for EDC through powder metallurgy method. In these types of electrode, green compact electrode has some characteristic and good deposition [6]. Samuel and Philip [7] have compared coating between conventional electrodes and $\mathrm{P} / \mathrm{M}$ electrodes in EDM. Electrolytic copper powder used as the electrode material at a sintering temperature and compaction pressure about $850^{\circ} \mathrm{C}, 500 \mathrm{MPa}$ respectively. Among $\mathrm{P} / \mathrm{M}$ electrode and conventional electrodes, $\mathrm{P} / \mathrm{M}$ electrodes are found to be more sensitive to pulse current and pulse on time. It can be observed that from this study, $\mathrm{P} / \mathrm{M}$ electrodes are technologically possible in EDM. Aspinwall [8] used 
$\mathrm{P} / \mathrm{M}$ electrodes, for surface modification by using EDM. Experimental work details the effects of EDM parameters on the hardness and composition of the white layer following die sink machining of AlS1 HI3 tool steel and roll texturing of $2 \% \mathrm{Cr}$ steel using partially sintered $\mathrm{P} / \mathrm{M}$ electrodes made of $\mathrm{WC} / \mathrm{Co}$. It can be observed that $\mathrm{WC} / \mathrm{Co}$ electrodes increased the surface hardness due to the presence of W, C and Co. Lee [9] prepared WC compact tool electrode under compaction pressure of 100 to $540 \mathrm{MPa}$ and a sintering temperature about $1000^{\circ} \mathrm{C}$. EDC experiments were conducted with range of current and voltages are of 8 to $12 \mathrm{~A}$ and 240 to $245 \mathrm{~V}$ respectively. It is observed from this study that the partially sintered electrode prepared by $\mathrm{P} / \mathrm{M}$ electrode can encourage surface modification because of the bonding between grains is reduced as compared to fully dense products. Shunmugan and Philip [10] used WC powder compact tool containing WC40\% and Fe $60 \%$. They achieved $25 \%$ to $60 \%$ improvement in abrasive wear resistance and $20 \%$ to $50 \%$ reductions in cutting forces with WC-coated HSS tools during machining. Even at extreme pressure and temperature conditions during metal cutting, WC coated HSS tools have exhibited improved wear resistance. Due to light weight and high specific strength, $\mathrm{Al}$ and its alloy has been used in the applications of automotive and aerospace industry as an alternative material for steel but it has limited for the wear resistance. In order to improve their wear resistance, surface coatings is a promising technique. The materials selected for tool electrodes are tungsten carbide (WC) and nickel (Ni) for surface modification due to its high hardness and wear resistance. The powder metallurgy route method has been used to fabricate tool electrode with combination of WC $60 \%$ and $\mathrm{Ni} 40 \%$ and Al6061 aluminium alloy used as workpiece material. By changing the polarity of EDM, the hard tungsten carbide layer has been deposited to increase the wear resistance of the aluminium workpice. The tool wear rate and metal transfer rate have been studied at various EDM parameters.

\section{Experimental procedures and planning}

The experiment was conducted with a tool electrode prepared by combining tungsten carbide and nickel with 60:40 weight percentages through $\mathrm{P} / \mathrm{M}$. Pestle and mortar made by ceramic has been used for mixing the WC/Ni powder. The dimensions of the punch and die utilized were $10 \mathrm{~mm}$ diameter respectively. These powders were mixed at different compaction load (1, 2 and 3 ton). Al6061 aluminium alloy was utilized as the workpiece material in this work. The chemical composition of base metal is depicts in table 1. Top and bottom faces of the work piece were ground to make flat and good surface finish prior to experimentation was made. The EDM experiments were conducted in 5530 EDM E-series machine. The machining was generally carried out for a fixed time interval and the amount of material transfer rate (MTR) and tool wear rate (TWR) was measured by taking the difference in weights of the workpiece and tool before and after electrical discharge machining using SF400D weighing machine with accuracy of $0.01 \mathrm{~g}$. The MTR and TWR were calculated by considering the experimental time as per Eqn. $1 \& 2$.

$$
\begin{aligned}
& \mathrm{MTR}=\frac{\text { weight of workpiece after experiment }(\mathrm{mg})-\mathrm{w} \quad \text { of workpiece before experiment }(\mathrm{mg})}{\text { Time taken for the experiment }(\mathrm{min})} \mathrm{mg} / \mathrm{min}--(1) \\
& \mathrm{TWR}=\frac{\text { weight of electrode after experiment }(\mathrm{mg})-\text { weig of electrode before experiment }(\mathrm{mg})}{\text { Time taken for the experiment }(\mathrm{min})} \mathrm{mg} / \mathrm{min}--(2)
\end{aligned}
$$

Table.1 Chemical composition of Al6061 aluminium alloy

\begin{tabular}{|l|l|l|l|l|l|l|l|l|}
\hline $\mathrm{Mg}$ & $\mathrm{Si}$ & $\mathrm{Fe}$ & $\mathrm{Cu}$ & $\mathrm{Ti}$ & $\mathrm{Cr}$ & $\mathrm{Zn}$ & $\mathrm{Mn}$ & $\mathrm{Al}$ \\
\hline 0.90 & 0.75 & 0.25 & 0.22 & 0.09 & 0.10 & 0.05 & 0.04 & Bal \\
\hline
\end{tabular}

Table 2: Process parameter and their level

\begin{tabular}{|l|l|l|l|l|}
\hline \multirow{2}{*}{ Parameter } & \multirow{2}{*}{ Unit } & Levels \\
\cline { 3 - 5 } & & -1 & 0 & 1 \\
\hline Compaction load (A) & Ton & 1 & 2 & 3 \\
\hline Current (B) & Amp & 3 & 4 & 5 \\
\hline Pulse on time ( C) & $\mu$ s & 50 & 60 & 70 \\
\hline
\end{tabular}




\section{Result and discussion}

The experimental results of metal transfer rate and tool wear rate are shown in table 3 . The experimental data was analyzed on the basis of central composite design of response surface methodology.

\section{Table 3: Experimental Results}

\begin{tabular}{|c|c|c|c|c|c|}
\hline Ex.No & $\begin{array}{l}\text { Compaction } \\
\text { load, Tonn }\end{array}$ & Current, A & $\begin{array}{l}\text { Pulse on time, } \\
\mu \mathrm{s}\end{array}$ & $\mathrm{MTR}, \mathrm{mg} / \mathrm{min}$ & $\mathrm{TWR}, \mathrm{mg} / \mathrm{min}$ \\
\hline 1 & 1 & 3 & 50 & 0.0116659 & 0.0245568 \\
\hline 2 & 3 & 3 & 50 & 0.0090659 & 0.0232568 \\
\hline 3 & 1 & 5 & 50 & 0.0229659 & 0.0505568 \\
\hline 4 & 3 & 5 & 50 & 0.0118659 & 0.0387568 \\
\hline 5 & 1 & 3 & 70 & 0.0254659 & 0.0533568 \\
\hline 6 & 3 & 3 & 70 & 0.0093659 & 0.0215568 \\
\hline 7 & 1 & & 70 & 0.0362659 & 0.0658568 \\
\hline 8 & 3 & 5 & 70 & 0.0116659 & 0.0235568 \\
\hline 9 & 8 & $\$ 6$ & $60 / 7$ & 0.0236364 & 0.0546727 \\
\hline 10 & 3 & 4 & 60 & 0.0100364 & 0.0328727 \\
\hline 11 & 2 & 3 & 60 & 0.0164364 & 0.0382727 \\
\hline 12 & 2 & 5 & 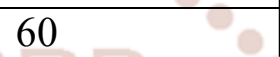 & 0.0202364 & 0.0522727 \\
\hline 13 & 2 & 4 & 50 & 0.0184364 & 0.0398727 \\
\hline 14 & $2>0$ & 4 & 70 & 0.0192364 & 0.0466727 \\
\hline 15 & $2+60$ & atio & 60 & 0.0161091 & 0.0473182 \\
\hline 16 & $2+0$ & 4 & 60 & 0.0161091 & 0.0473182 \\
\hline 17 & 230 & 4 lienol & $60 \mathrm{clent}$ & 0.0181091 & 0.0473182 \\
\hline 18 & 20 & 4 & 60 & 0.0171091 & 0.0473182 \\
\hline 19 & $2>$ & 4 & 60 & 0.0161091 & 0.0473182 \\
\hline 20 & $2 \Rightarrow$ & Deve & 60 ment: & 0.0151091 & 0.0473182 \\
\hline
\end{tabular}

\subsection{Effect of process parameter on MTR}

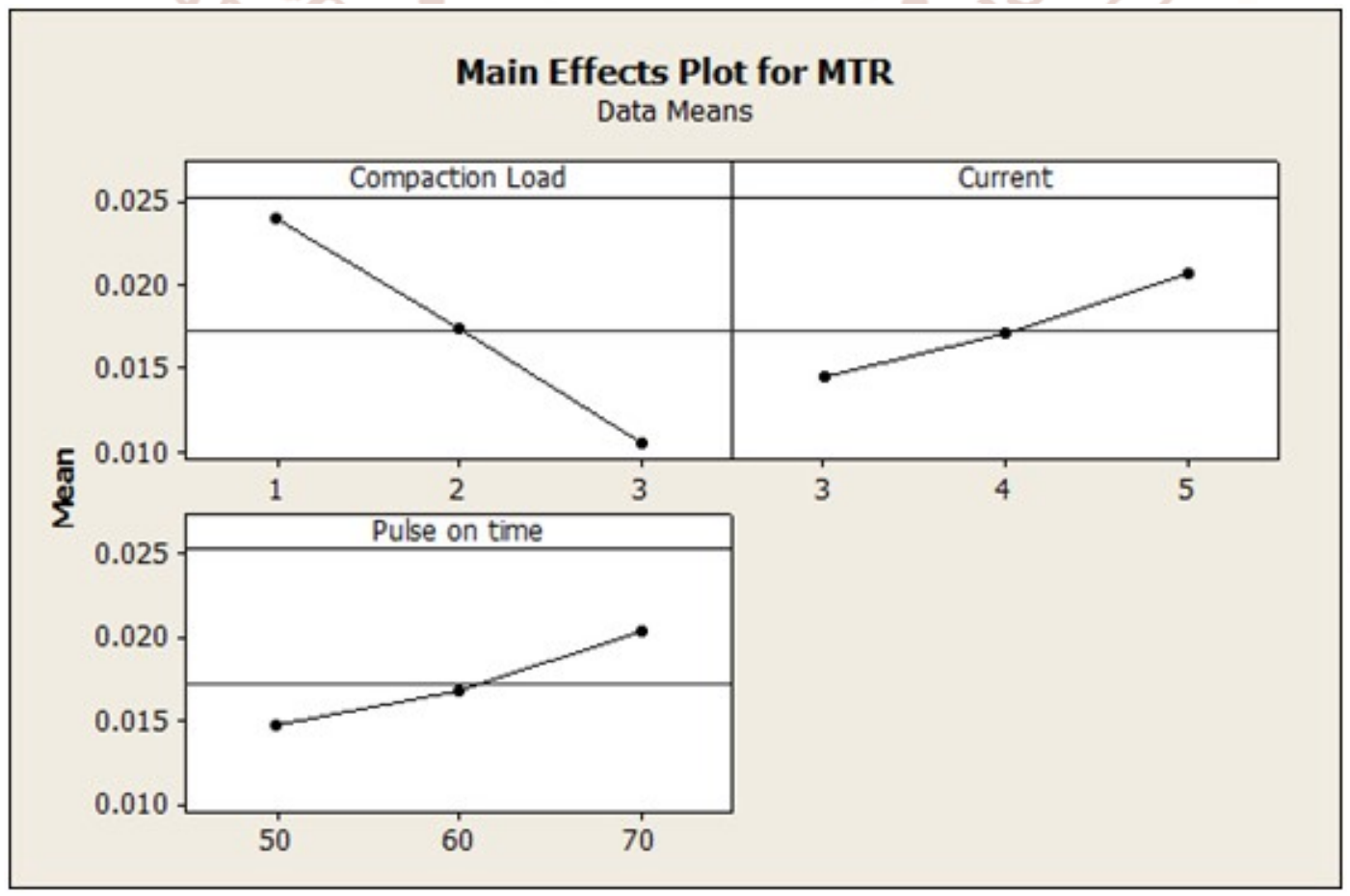

Figure 1 Effects of Process parameters on MTR 
Effect of EDM parameters on metal transfer rate by main effect plot is shown in figure1. From the figure it has been observed that compaction load increases MTR decreases. Therefore, huge amount of metal deposition can be obtained for tool prepared at lower compaction load. This is because at higher compaction load the tool materials are firmly bonded and the bond between the powder particles is strong enough to reduce the metal transfer rate from the powder compacted electrode to $\mathrm{Al}$ work piece. When peak current is increasing from $3 \mathrm{~A}$ to $4 \mathrm{~A}$ the deposition rate is also increasing. Further increases the current from 4A to 5 A, MTR increases linearly. The reason is that, during electro discharge process at high current more material is disintegrated from the powder compacted electrode and deposited on the substrate surface. At higher current due to strong spark there is a possibility to removal of some pre-deposited coating layer or substrate material, which causes an overall reduction in deposition rate. When pulse on time increases from 50 to $60 \mu$ s the MTR is also increases. At higher pulse on time, it has a more dominant effect on input energy. Due to the higher temperature generated more powder material is eroded from the electrode.

\subsection{Effect of process parameter on TWR}

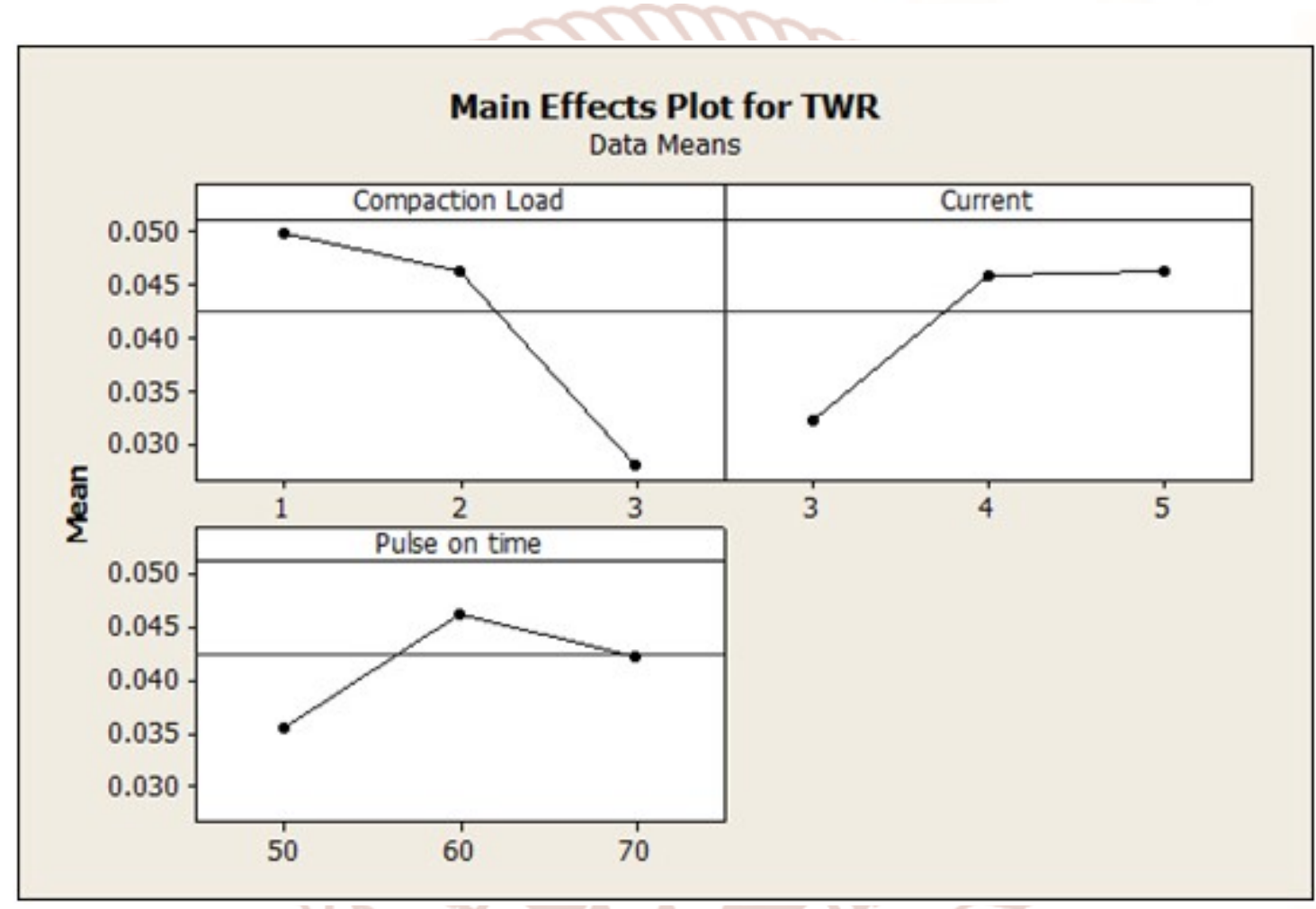

Figure 2 Effects of Process parameters on TWR

Effect of process parameters of EDC on tool wear rate by main effect plot is shown in Figure 2. It is clear from the plotted graph that, the tool wear rate is more for using electrode prepared at lower compaction load and less for tool prepared at higher compaction load. This is because of the lower binding energy of the powder particles at low compaction load which enhances the erosion of tool material. The tool wear rate is increases as peak current increases during EDC process. The higher peak current has a dominant effect on input energy and hence more temperature is generated during sparking which melted and eroded tool electrode at faster rate and at the end tool wear rate is increased. Tool wear rate is increases when pulse on time increases due to the strong spark generation during discharge. But when pulse on time is further increased tool wear rate is rapidly decreased. The main reason for this, at high pulse on time more heat is generated and hence volume of discharge has increased. But energy density on the discharge spot will reduce and there will be an undesirable heat loss which will not contribute to material removal from tool and hence tool wear rate will reduce. 


\section{Microstructure analysis}

Scanning electron microscopy (SEM) is one of the best techniques to produce the magnified images of the surface structures. The SEM images of deposited layer are shown in the Figure 3. From these micrographs, the following observations can be made:

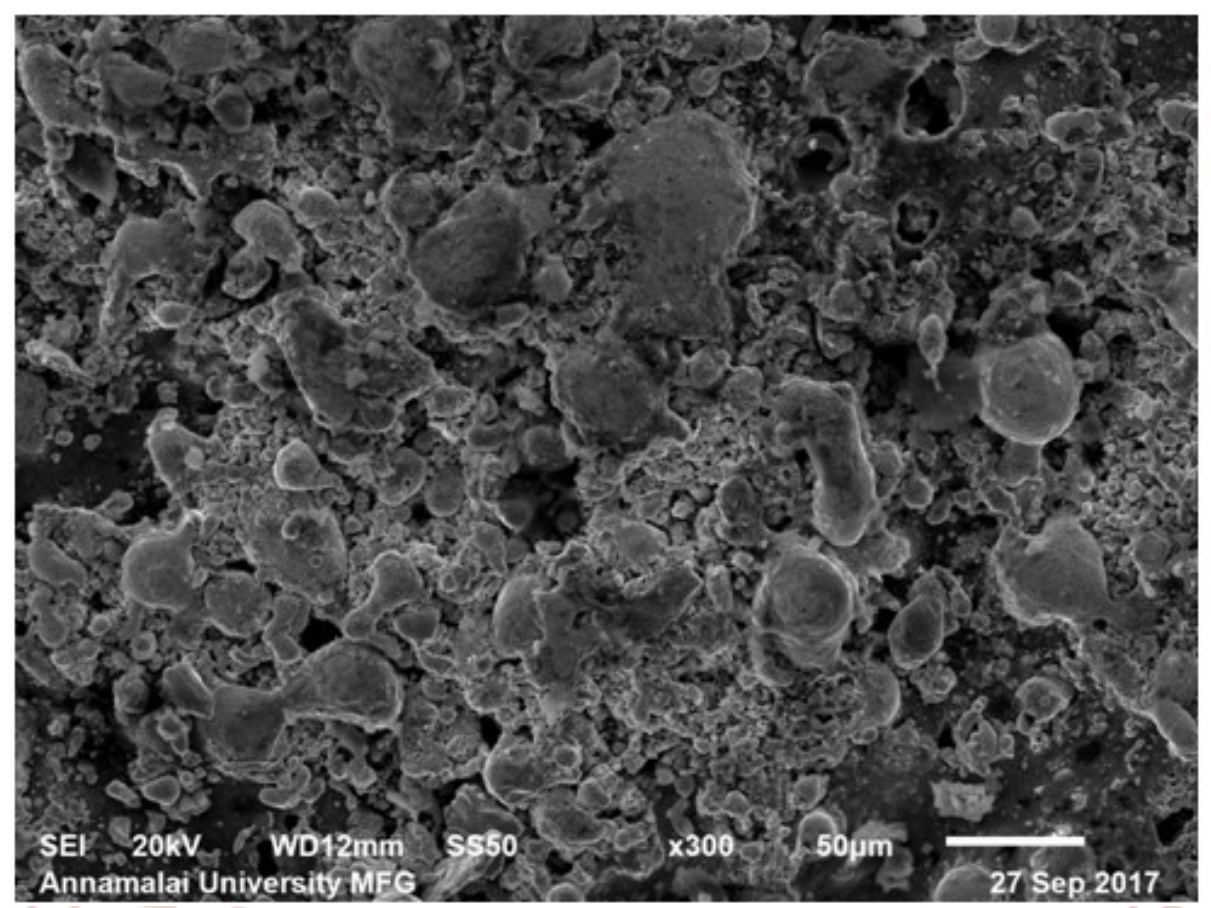

Figure 3 Bulk depositions with globular grain and craters

From Figure 3, uniform thick lump deposition of the materials with deep craters of globular grain size can be observed very clearly on deposited surface, this is due to the high current and pulse on time which melts the WC, due to its high density WC will be deposited in the form of lumps on the substrate surface. From fig. 4 uniform thin deposition with low deep craters can be observed, this is due to the low current and pulse on-time.

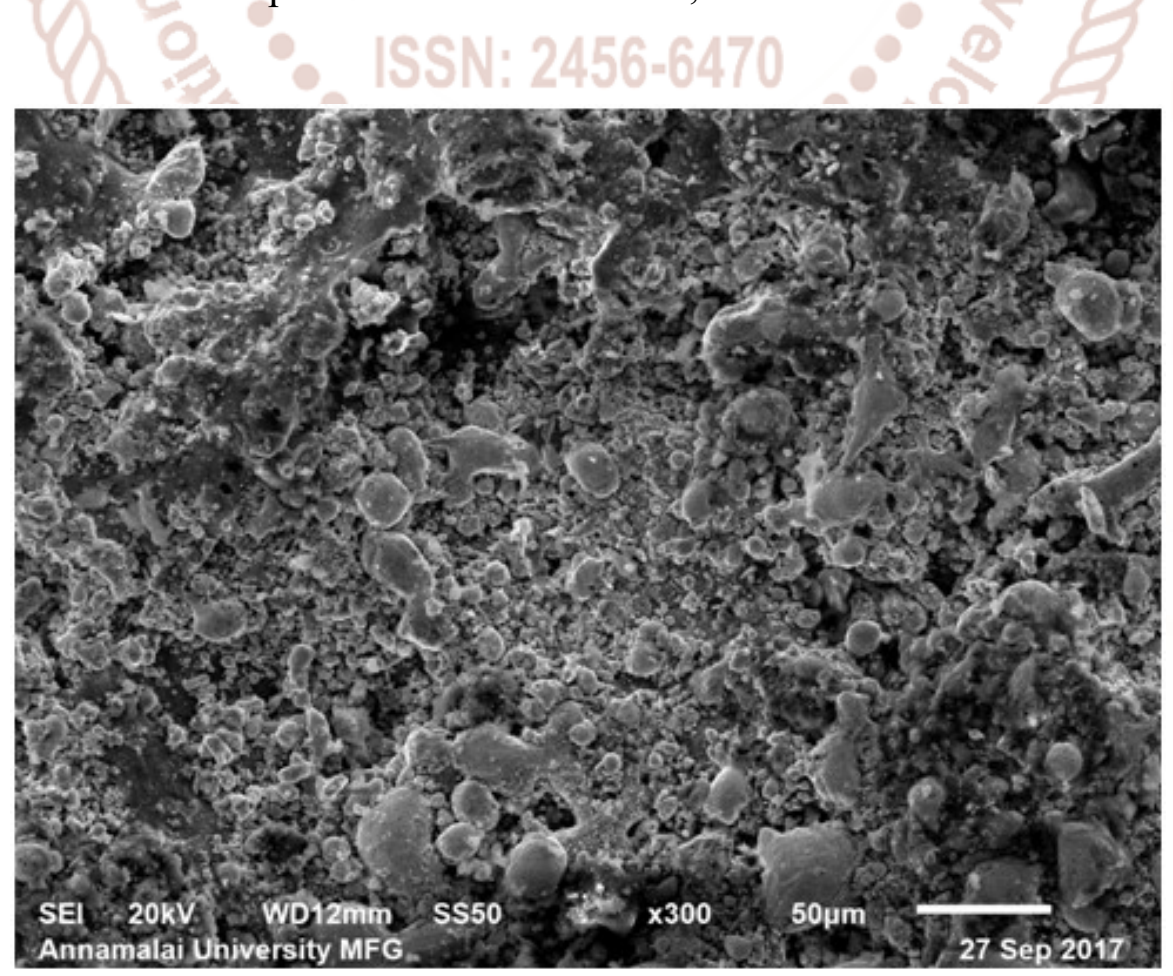

Figure 4 Thin depositions with small craters 


\section{Conclusion}

WC-Ni composite layer has been deposited successfully over Al work-piece surface by Electro Discharge Coating process. From the experimental results, it is found that, at high compaction load, bonding between powder particles is strong enough to reduce material transfer rate from tool electrode to work-piece material. Hence tool wear rate and deposition rate is reduces with increase in tool compaction load. Again, with increase of peak current (Ip), both deposition rate and tool wear rate increases due to faster rate of disintegration and deposition of powders from compacted tool electrode to the substrate surface. It is further observed that, when pulse on time (Ton) increases both depositions rate and tool wear rate increases that are mainly due to generation of high temperature and corresponding erosion of powder material from the tool electrode.

\section{References}

1. Anil, K.; Sachin, M.; Sharma, C. Naveen, B. Research developments in additives mixed electrical discharge machining (AEDM): a state of art review. Materials and Manufacturing Processes 2010, 25 (10), 1166-1180.

2. Hsin-Jen, C.; Kun-Ling, W.; Biing-Hwa, Y. Dry electrical discharge coating process on aluminum by using titanium powder compact electrode. Materials and Manufacturing Processes 2013, 28 (12), 1286-1293.

3. Abbas, M.M.; Solomon, D.G.; Bahari, M.F. A review on current research trends in electrical discharge machining. International Journal of Machine Tools and Manufacture 2007, 47(7-8), 1214-1228.

4. .Kumar, S.; Singh, R.; Singh, T.P.; Sethi, B.L. Surface modification by electrical discharge machining: A review. Journal of Materials Processing Technology 2009, 209, 3675-3687.

5. Singh, S. Current research trends in variants of electrical discharge machining: A review. International Journal of Engineering Science and Technology 2010, 2 (6), 2172-2191.

6. Z.L. Wang,Y.Fang, P.N.Wu, W.S. Zhao, K. Cheng, Surface modification process by electrical discharge machining with a Ti powder green compact electrode, Journal material processing technology 129 (2002) 139-142.
7. Samuel, M. P. and Philip, P.K. (1996), Powder metallurgy electrodes for electrical discharge machining, Journal of Machine Tools Manufacturing, Vol.37, pp.1625-1633.

8. Aspinwall, D.K; Dewes, R.C,Lee, H.G and Simao, J. Electrical Discharge Surface Alloying of Ti and Fe Workpiece Materials Using Refractory Powder Compact Electrodes and $\mathrm{Cu}$ Wire.

9. Lee, H. G; Simao, J; Aspinwall, D. K. and Dewes, R. C. (2004), Electrical discharge surface alloying, Journal of Material Processing Technology, Vol.149, pp. 334-340.

10. Shunmugan, M.S; Philip, P.K. and Gangadhar, A. (1994), Improvement of wear resistance by EDM with tungsten carbide $\mathrm{P} / \mathrm{M}$ electrode, Wear, Vol. 171 , pp. $1-5$. 